Pesquisa e Reflexão em Educação Básica

\title{
Percurso histórico da educação especial à educação inclusiva em Moçambique: análise de políticas educacionais 1990-2019
}

\begin{abstract}
Resumo:
Este trabalho é resultado das reflexões sobre a inclusão de alunos com necessidades educativas especiais (NEE) nas escolas de ensino comum em Moçambique. Aponta-se como problemática a questão: quais dinâmicas foram traçadas para a inclusão desses alunos, considerando as diretrizes internacionais? Para efetivação deste trabalho, recorreu-se aos pressupostos da pesquisa qualitativa, com foco na análise de documentos normativos que tratam das políticas educacionais, subsidiada por trabalhos já realizados. As análises foram realizadas à luz das contribuições do pensamento sistêmico. $\mathrm{O}$ artigo analisa as políticas educacionais, com foco na inclusão escolar, considerando o percurso histórico da educação especial e a influência das instituições multilaterais na educação. Para esta discussão, parte-se do pressuposto de que as políticas educacionais refletem as intenções e as ações do governo e as escolas são tomadas como espaço de "implementação" dessas políticas a partir das matrículas de alunos com NEE. Discutir as políticas educacionais significa abordar as reformas contidas nos documentos normativos que supõem uma reorganização dos subsistemas de ensino, da inclusão escolar e da melhoria da qualidade de ensino. Os resultados demonstram que as políticas educacionais são abrangentes, mas, se pensadas no contexto da inclusão de alunos com $\mathrm{NEE}$, ainda não respondem às necessidades desses alunos.
\end{abstract}

\section{Palavras-chave:}

Inclusão escolar. Escolas de ensino comum. Necessidades educativas especiais. Documentos normativos.

\section{Historical path from special education to inclusive education in Mozambique: analysis of educational policies 1990-2019}

\section{Abstract:}

This work is the result of reflections on the inclusion of students with special educational needs in ordinary schools in Mozambique. It's appointed as problematic the following question: which dynamics were outlined for the inclusion of students with EEN in Mozambique, considering the international

1 Doutora em Educação pela Universidade Federal do Rio Grande do Sul. Professora na Universidade Eduardo Mondlane Moçambique. E-mail: delfi.silva@gmail.com. ORCID iD: https://orcid.org/0000-0002-6313-7149. 
guidelines to which the country is a signatory? To carry out this work, qualitative research was used as a premise in which was focused on the analysis of normative documents that deal with educational policies in the country, subsidized by works already carried out which discuss the subject. The research was carried out in the light of the contributions of systemic thinking, specifically the epistemological assumptions of complexity, instability, and intersubjectivity. This article analyzes educational policies, with a focus on school inclusion, considering the historical path of special education and the influence of multilateral institutions on education legislation in Mozambique. For this discussion, it's assumed that educational policies reflect the intentions and actions of the government in the field of education, and schools are taken as a space for "implementing" these educational policies from the receipt of the enrollment of students with special educational needs. It's assumed in this paper that discussing educational policies means addressing the reforms contained in the normative documents that suppose a reorganization of the various teaching subsystems, school inclusion, and improving the quality of teaching. The results demonstrate that educational policies are comprehensive, but, if considered in the context of the inclusion of students with special educational needs, they still do not respond to the needs of this group of students.

\section{Keywords:}

School inclusion. Common teaching schools. Special educational needs. Normative documents.

\section{Recorrido histórico de la educación especial a la educación inclusiva en Mozambique: análisis de políticas educacionales 1990-2019}

\section{Resumen:}

Este trabajo es resultado de las reflexiones sobre la inclusión de alumnos con necesidades educativas especiales (NEE) en las escuelas de enseñanza básica en Mozambique. Se apunta como problemática la siguiente cuestión: ¿cuáles dinámicas fueron trazadas para la inclusión de alumnos con NEE en Mozambique, considerando las directrices internacionales de las cuales el país es signatario? Para la concretización de este estudio, se recurrió a los presupuestos de la investigación cualitativa, con foco en el análisis de documentos normativos que tratan de las políticas educacionales en el país, subsidiado por trabajos ya concluidos y que discuten el asunto. Los análisis fueron realizados a la luz de las contribuciones del pensamiento sistémico, específicamente las premisas epistemológicas de la complejidad, instabilidad e intersubjetividad. El presente artículo analiza las políticas educacionales, con foco en la inclusión escolar, considerando el recorrido histórico de la educación especial y la influencia de las instituciones multilaterales en la legislación de la educación en Mozambique. Para esta discusión, se parte del presupuesto de que las políticas educacionales reflejan las intenciones y las acciones del gobierno en el ámbito de la educación, y las escuelas son tomadas como espacio de "implementación" de esas políticas educativas a partir del recibimiento de la matrícula de alumnos con necesidades educativas especiales. Asumimos en este trabajo que discutir las políticas educacionales significa abordar las reformas contenidas en los documentos normativos que suponen una reorganización de los diversos subsistemas de enseñanza, de la inclusión escolar y de la mejoría de la cualidad de enseñanza. Los resultados demuestran que las políticas educacionales son abarcadoras, pero, si pensadas en el contexto de la inclusión de alumnos con necesidades educativas especiales, todavía no responden a las necesidades de ese grupo de educandos.

\section{Palabras clave:}

Inclusión escolar. Escuelas de enseñanza básica. Necesidades educativas especiales. Documentos normativos. 


\section{Introdução}

Moçambique esteve sob a dominação portuguesa até meados da década de 1970. Dessa dominação, resultou um sistema segregacionista e elitista que promovia desigualdades sociais dentro do sistema colonial. Esse sistema começa a ser superado a partir de $1975 \mathrm{com}$ a conquista da independência, e são adotadas novas políticas educacionais, com foco na criação de um homem novo, livre da colonização e dotado de conhecimentos científicos no contexto dos princípios do socialismo. A partir da segunda metade da década de 1980, começam a ser adotados os princípios da perspectiva capitalista.

Na década de 1990, com a eclosão de movimentos educacionais, como a Declaração de Jomtien (1990), a Declaração de Salamanca (1994) e a de Dakar (2000), Moçambique sendo signatário dessas declarações foi impulsionado a repensar as políticas educacionais no sentido de responder a esse movimento educacional. Foi a partir desse período que os técnicos do Ministério da Educação começaram a participar dos encontros organizados pelo Instituto de Inovação Educacional de Portugal, para pensar nas possibilidades da inclusão de alunos com necessidades educativas especiais $^{2}$ nas escolas de ensino comum nos Países Africanos de Língua Oficial Portuguesa (PALOP).

Em 1998, inicia a implementação do Projeto Escolas Inclusivas, a partir do qual os alunos com deficiência passam a ter mais acesso às escolas de ensino comum, conforme orientava a Declaração de Salamanca. É a partir dessa premissa que surge a seguinte questão: como estão sendo delineadas as políticas de inclusão escolar, considerando as diretrizes internacionais, das quais o país é signatário e as condições reais do país? Para responder a esse questionamento, decidiu-se analisar o percurso da educação especial, com atenção aos momentos históricos que caracterizam a educação e aos documentos normativos que orientam a inclusão escolar no país.

O presente artigo tem como objetivo analisar o percurso histórico da educação especial e educação inclusiva em Moçambique, tomando como marco temporal o período de 1990 a 2019. Para a efetivação deste trabalho, foram levados em consideração os pressupostos apresentados na Declaração de Salamanca e em outros documentos elaborados em nível internacional. Assim, recorreu-se aos pressupostos da pesquisa qualitativa, com foco na análise documental, que consistiu na análise dos dispositivos normativos que tratam das políticas educacionais no país. Gil (2008) considera que a pesquisa bibliográfica permite ao pesquisador obter uma informação ampla sobre o assunto pesquisado. Desse modo, foi realizado um levantamento bibliográfico de trabalhos acadêmicos que discutem a temática. Foi possível identificar que, no contexto moçambicano, alguns trabalhos foram desenvolvidos e os trabalhos de Chambal (2012) e de Nhapuala (2014) serviram como potenciais para o enriquecimento do nosso debate.

Moçambique conquistou sua independência em 1975 e, em seguida, em 1976, os serviços de educação, saúde e justiça foram nacionalizados, passando para a gestão do Estado. A nacionalização tinha como objetivo romper com os elementos de desigualdade social perpetuados pelo sistema colonial e possibilitar a planificação da ação educativa com vistas à criação de um sistema de educação que servisse à população moçambicana.

O termo "política" é polissêmico, apresentando três dimensões: polity vista como a esfera institucional, a politics como a atividade política e a policies como ação pública, e a política pública em si (MULLER; SUREL, 2002). Constitui objeto de estudo do campo de conhecimento das políticas públicas as ações públicas (policies). Os outros dois sentidos são referenciados, pois apontam para as dimensões que se entrelaçam às políticas públicas (FARENZENA, 2011). A política pública

2 Ao longo deste texto, utilizaremos o conceito de necessidades educativas especiais para nos referirmos àqueles alunos que necessitam de apoio especializado da educação especial. Referir que, em Moçambique, as diretrizes educacionais e os dispositivos normativos usam esse conceito para fazer referência a esse grupo de alunos. 
em análise neste trabalho é entendida como constructo social por configurar as ações do governo com vista à solução de um problema identificado.

Partindo dessa compreensão de política pública como constructo social e um constructo de pesquisa (MULLER; SUREL, 2002), o referencial teórico-analítico deste trabalho é sustentado pelos pressupostos do pensamento sistêmico, por considerar que a organização autopoiética é o que caracteriza os seres vivos como sistemas auto-organizadores em contínua produção de si mesmos, fechados operacionalmente, mas em contínua interação com o meio (MATURANA; VARELA, 2001). Os pressupostos epistemológicos da complexidade, instabilidade e intersubjetividade são considerados essenciais na condução deste trabalho, pelo reconhecimento de que não há uma única realidade, mas múltiplos olhares e dimensões que possibilitam diversificadas interpretações e descrições de cada um dos fenômenos analisados (VASCONCELLOS, 2016). Ao assumir os pressupostos do pensamento sistêmico, não buscamos olhar para partes isoladas do objeto, mas as relações entre os diferentes elementos envolvidos na situação em análise que integram o nosso contexto. Além disso, através do referencial teórico do pensamento sistêmico, pretendemos romper com as bases epistemológicas dos paradigmas conservadores, bem como com a visão linear do mundo, aquela visão de causa-efeito.

O país tem uma população estimada em 27.909.798, sendo 13.348.446 do sexo masculino e 14.561.352 do sexo feminino. Dessa população, 727.620 são pessoas com algum tipo de deficiência, sendo 372.061 do sexo masculino e 355.559 do sexo feminino, segundo os dados do Instituto Nacional de Estatística (MOÇAMBIQUE, 2017). O país possui uma diversidade cultural e linguística com mais de vinte línguas nacionais, a maioria são de origem autóctones do grupo bantu e outras são oriundas do continente asiático. Grande parte da população desenvolve primeiro a língua materna e só aprende a língua portuguesa no contexto escolar. Com a conquista da independência, foi oficializada a língua portuguesa como língua da unidade nacional, no sentido de uniformizar e facilitar a comunicação pelo país, pois nenhuma das línguas nacionais possui uma maioria falante na mesma região.

Quanto à taxa de analfabetismo, os dados do Instituto Nacional de Estatística (INE) indicavam que, em 2017, a taxa de analfabetismo era de $39 \%$, sendo que os homens apresentavam uma taxa de $27,2 \%$ e as mulheres $49,4 \%$. As zonas rurais apresentam taxas elevadas de $50,7 \%$ em comparação com as zonas urbanas, que têm uma taxa de $18,8 \%$.

Este artigo obedece à seguinte estrutura: na primeira parte, apresentamos a introdução com a intenção de descrever de forma breve o contexto da pesquisa. Na segunda parte, apresentamos a educação especial no país, iniciando pelo período colonial, seguida pela educação da década de 1990 até a atualidade, destacando o papel dos documentos internacionais nas políticas do país e finalizamos com os possíveis direcionamentos (perspectivas) da educação inclusiva.

\section{A educação em Moçambique}

\section{A educação do período colonial até 1990}

Moçambique é um país situado no sudoeste da África, limitado ao norte pela República da Tanzânia, ao sul pela República da África do Sul, ao oeste pelas Repúblicas do Malawi, da Zâmbia e do Zimbabwe e, pelo reino da Suazilândia; a leste é limitado pela faixa costeira banhada pelo Oceano Índico numa extensão de $2.470 \mathrm{~km}$. O País foi colônia de Portugal e conquistou sua independência em 25 de junho de 1975. Atualmente, tem onze províncias e aproximadamente 799.380 $\mathrm{km}^{2}$ de extensão territorial.

A educação em Moçambique remonta os períodos da colonização, em que esta era apenas oferecida aos filhos dos brancos; passando, posteriormente, a ser ofertada para os moçambicanos 
que tivessem adquirido o estatuto de assimilado ${ }^{3}$. Essa educação era oferecida nas missões da Igreja Católica, instituição que desempenhou um papel de destaque na educação do país (MAZULA, 1995). As primeiras escolas de educação especial foram criadas na década de 1960, cujo funcionamento foi instruído pelo Diploma Legislativo $\mathrm{n}^{\circ} 2.288$, e as orientações eram oriundas da metrópole, pois o país era colônia de Portugal. Essas escolas tinham como finalidade "recuperar" aquelas crianças que apresentavam atrasos de educação e funcionavam de acordo com as orientações estabelecidas pela direção dos serviços de instrução para as escolas de ensino regular (MOÇAMBIQUE, 1996).

Em 1976, o ensino foi nacionalizado através do Decreto n¹2/75 (MOÇAMBIQUE, 1975), por meio do qual o Governo passou a assumir inteiramente a responsabilidade da educação e instrução dos cidadãos, sendo os programas de ensino uniformizados de acordo com as necessidades do país. Em 1983, é aprovada a Lei 4/83 do Sistema Nacional de Educação, que foi revogada pela Lei 6/92 que, por sua vez, foi reformulada pela atual Lei 18/2018, com a finalidade de se ajustar às necessidades do país e às normas vigentes nos países vizinhos (MOÇAMBIQUE, 2018).

O ensino no período colonial era caracterizado por práticas da educação portuguesa, com o auxílio da Igreja Católica por meio da ação de missionários. De acordo com Mazula (1995), a educação nesse período era somente para os brancos, cabendo ao negro uma pequena instrução para o trabalho e para atender aos interesses do colonialismo. Esse sistema foi marcado pela dominação e pelo enfraquecimento do povo moçambicano, pois só podia aprender e incorporar os costumes dos portugueses.

O período pós-independência, até a década de 1990, foi marcado pela guerra civil que iniciou em 1976, motivada pelas desavenças ideológicas entre dois partidos políticos: a FRELIMO ${ }^{4}$ e a RENAMO $^{5}$. As calamidades naturais e a entrada das agências multilaterais também constituíram elementos que marcaram esse período histórico. Durante a guerra civil, o país passou por uma crise econômica "grave" e teve que recorrer às instituições financiadoras em busca de ajuda. Uma das condições impostas foi o abandono do sistema socialista e a adoção da perspectiva capitalista. Essa mudança culminou com a alteração na Constituição da República em 1990 e, consequentemente, a mudança da Lei 4/83 para a Lei 6/92 do Sistema Nacional de Educação. Com a adesão do país ao Fundo Monetário Internacional (FMI) e ao Banco Mundial (BM), teve início a adoção da política neoliberal que levou à consagração da Constituição da República de 1990 e posteriormente a de 2004.

A título de exemplo, o artigo 4 da Lei 4/83 refere que o Sistema Nacional de Educação tem como objetivo a "[...] formação do homem novo, um homem livre do obscurantismo, da superstição e da mentalidade burguesa e colonial, um homem que assume os valores da sociedade socialista [...]" (MOÇAMBIQUE, 1983, p. 2, grifo nosso). Nesse contexto, pode-se perceber que as questões políticas de cunho socialista eram dominantes no sistema de ensino.

Em 1986, o Departamento de Educação Especial criou, nas escolas de ensino comum, "turmas diagnósticas", com a finalidade de atender aqueles alunos que apresentavam problemas de aprendizagem (repetência mínima de dois anos na mesma classe). Esses alunos frequentavam em um turno a turma regular e em outro a turma especial, para receber aulas e ter acompanhamento psicopedagógico. Essa prática pode ser entendida como tendo semelhanças ao que ocorre no Brasil, em função de uma perspectiva de complementaridade com o atendimento que é oferecido ao público-alvo da educação especial por meio da expansão das salas de recursos, como estabelece a Política Nacional de Educação Especial na Perspectiva de Educação Inclusiva de 2008 (BRASIL, 2008).

Os resultados alcançados com a implementação dessas turmas foram considerados positivos pelos técnicos do Departamento de Educação Especial do Ministério da Educação. A partir dessa

\footnotetext{
3 Entende-se por assimilado o indivíduo que tenha o domínio da língua portuguesa na fala e na escrita, que fosse capaz de se relacionar com o mundo dos brancos e que assimilara a cultura do colonizador.

4 FRELIMO: Frente de Libertação de Moçambique.

5 RENAMO: Resistência Nacional Moçambicana.
} 
atividade, foi possível identificar e intervir de modo a minimizar as dificuldades de aprendizagem desses alunos, mas, por razões desconhecidas, não foi possível dar continuidade à implementação das turmas diagnósticas.

A necessidade de atender a situações criadas pela guerra e pelas calamidades naturais impeliu o Governo, em 1987, com a Instrução Ministerial no 5/87 à criação do Núcleo de Emergência (MOÇAMBIQUE, 1987). A partir dessa instrução, o Departamento de Educação Especial do Ministério da Educação desenvolveu um programa de atividades de atendimento às crianças e aos professores em situação de vulnerabilidade, tendo utilizado como metodologia de trabalho a capacitação de professores e técnicos do Ministério da Educação em técnicas de identificação das necessidades dos alunos e a elaboração de material e manuais de apoio. O programa tinha como objetivo apoiar crianças em idade escolar afetadas pela guerra e outras condições adversas (MOÇAMBIQUE, 1996).

Da experiência adquirida e das evidências de sucesso a partir dos diversos programas que foram implementados na época, pode-se considerar que se estava na presença de um processo de inclusão no contexto moçambicano. Os alunos já estavam "integrados" na escola de ensino comum e as suas necessidades eram identificadas e atendidas, ainda que de forma não abrangente. No entanto, o paradigma integracionista e toda a organização estrutural vigente na época, bem como ausência de financiamento para continuar com os programas, constituíram recuos marcantes.

Ao analisar a Lei 4/83, no seu artigo dezoito, refere que constitui o objetivo do "ensino especial" proporcionar uma formação que permita a integração dessas crianças e desses jovens na sociedade e na vida laboral (MOÇAMBIQUE, 1983). Diante dessa lei, pode-se perceber que a educação de pessoas com deficiência estava plasmada nas políticas do país, sinalizando que estavam sendo "atendidos" os seus direitos humanos.

É diante desse cenário histórico que vão sendo registradas matrículas de alunos com deficiência nas escolas especiais. Em 1990, frequentavam o EP1 cerca de 1.200 .000 alunos e apenas 137 estavam matriculados nas escolas especiais (MOÇAMBIQUE, 1996).

De um modo geral, quando considerado o número total de matrículas em cada período, verifica-se que o número de alunos com deficiência é pouco significativo em relação ao número total de matrículas. Isso mostra que os alunos com deficiência não tiveram acesso ao sistema de ensino durante esse período, aliado ao fato da deficiência no contexto moçambicano ainda ser vista como castigo de Deus aos progenitores da pessoa com deficiência (SIMBINE, 2016). Nesse sentido, muitas famílias optam por manter as crianças em casa, como forma de protegê-las da discriminação e do preconceito na sociedade.

A escolaridade das crianças e dos adolescentes no ensino especial, até a década de 1980, atingia apenas o primeiro ciclo do ensino primário. Ao concluir esse nível, os alunos não tinham a possibilidade de continuar os estudos. Somente na década de 1990 é que foi introduzida a matrícula desses alunos no segundo ciclo do ensino primário. O país esteve exposto a fenômenos desestruturantes como a guerra civil, as calamidades naturais e a crise econômica, tais fenômenos tiveram como consequência a redefinição do papel do Estado. É a partir desse contexto que emergem novos atores políticos e as políticas educacionais passam a receber o apoio dos organismos internacionais.

As diretrizes presentes na Declaração de Salamanca passam a influenciar as políticas educacionais para educação inclusiva em Moçambique. No cerne dessa Declaração, está a obrigatoriedade de as escolas tornarem-se inclusivas, respondendo às necessidades dos alunos com deficiência, contrapondo-se à integração, na qual o aluno deveria adaptar-se às condições da escola. No âmbito da perspectiva da inclusão, as escolas passam a oferecer condições de aprendizagem, acesso e permanência desses alunos, observando também as questões específicas relativas à sua aprendizagem. 
Uma mudança na política pública surge em resposta aos problemas identificados em um determinado contexto, ou seja, existem motivações políticas, sociais ou históricas que levam a essa mudança da política. A situação política em que o país se encontrava, levou à revisão e à aprovação da Constituição da República em 1990.

A partir dessa Constituição, são adotados novos princípios que passam a orientar a educação, estabelecendo que a educação é um direito de todos os cidadãos. Essa Constituição levou à aprovação da Lei 6/1992 do Sistema Nacional de Educação, que revoga a Lei 4/1983. A partir da nova Lei, passa a constituir um dos objetivos da educação: "[...] erradicar o analfabetismo de modo a proporcionar a todo o povo o acesso ao conhecimento científico e o desenvolvimento pleno das suas capacidades" (MOÇAMBIQUE, 1992, p. 1).

A Lei 6/1992, no artigo nove, estabelece que constitui objetivo do ensino especial "[...] proporcionar uma formação em todos os graus de ensino e capacitação vocacional que permita a integração dessas crianças e jovens em escolas regulares, na sociedade e na vida laboral" (MOÇAMBIQUE, 1992, p. 4). Ao considerar as diretrizes apontadas nessa lei, percebemos que esta ainda não responde às exigências da inclusão escolar, pois os alunos com deficiência devem ser escolarizados nas escolas especiais e/ou em turmas especiais. Ainda prevalece a integração desses alunos e não necessariamente a inclusão.

O período de 1990 a 1997 é caracterizado por respostas políticas ao sistema educacional, visto que o país ratificou vários documentos internacionais e regionais, e estava dando início à formulação de políticas educacionais inclusivas. Nesse sentido, foram ratificados os seguintes documentos: Declaração de Jomtien que resultou no documento sobre a Educação para Todos (1990); a ratificação da Declaração de Salamanca e o Quadro de Ação para as Necessidades Educativas Especiais (1994).

Em 1995, foi elaborada a Política Nacional de Educação, que reafirma a "integração" dos alunos com deficiência. "A maior parte dessas crianças será 'integrada' em escolas normais ${ }^{6}$, com um sistema de apoio diferenciado. Professores capacitados sobre técnicas e metodologias de atendimento especial serão responsáveis por essas crianças" (MOÇAMBIQUE, 1995 p. 5). Nesse documento é estabelecido ainda que as crianças com deficiência podem ser divididas em dois grupos, segundo o grau da deficiência, sendo que aquelas consideradas "mais graves" serão atendidas em escolas especiais e as que apresentam menor grau podem ser enquadradas nas escolas de ensino comum. Para isso, será feita uma avaliação diagnóstica antes do início da escolarização desses alunos. Ao assumir essa proposição diagnóstica, corremos o risco de perceber o mundo como linear. Todavia, os fenômenos que envolvem os seres vivos não devem ser tomados como de ocorrência monocausal, pois são de ocorrências de causas múltiplas e de difícil apreensão (BAPTISTA, 2008).

O paradigma da complexidade nos possibilita compreender que as partes são constituintes de um todo e estão correlacionadas, mas que o todo não pode ser visto apenas como a soma das partes. Ao proceder a leitura desse documento, percebemos que este enfatiza a formação de professores para o sucesso da inclusão escolar. Nesse contexto, não podemos assumir que investindo na capacitação de professores, sem investir em outros profissionais, corremos o risco de responsabilizar apenas ao professor pelo sucesso da inclusão escolar. Além disso, é necessário considerar a participação dos diversos atores que compõem a rede que se refere aos processos inclusivos nas escolas, dentre os quais, os professores, a gestão, os diferentes profissionais da escola, as famílias, os profissionais que atendem o aluno fora da escola, etc.

Ao analisar esse documento, percebemos que esse não faz referência ao profissional responsável por tal avaliação das crianças antes do ingresso na escola. Assim, questionamos o seguinte: 
quem seria responsável por essa avaliação: o professor ou o profissional de saúde? Ao estabelecer a avaliação diagnóstica para aferir o grau ou o tipo de deficiência, estaríamos valorizando o modelo médico da deficiência, aquele que defende que a pessoa com deficiência não será bem-sucedida no percurso acadêmico.

O período em análise é marcado pela aprovação da Lei 6/92, pela aprovação da Política Nacional de Educação em 1995 e pela adesão às orientações estabelecidas na Declaração de Jomtien e Declaração de Salamanca. Esses movimentos nas políticas educacionais podem ser lidos como sinais de avanço na educação inclusiva.

Para Mantoan (2006), as escolas inclusivas propõem um modo de organização do sistema educacional que considera as necessidades de todos os alunos e que é estruturado em função dessas necessidades. O processo da inclusão exige mudança e envolvimento de todos, abrindo espaço para todos alunos e não somente para aqueles com algum tipo de deficiência

[...] a inclusão implica uma mudança de perspectiva educacional, porque não atinge apenas os alunos com deficiência e os que apresentam dificuldades de aprender, mas todos os demais, para que obtenham sucesso na corrente educativa geral. Os alunos com deficiência constituem uma grande preocupação para os educadores inclusivos. Todos sabemos, porém, que a maioria dos que fracassam na escola são alunos que não vêm do ensino especial, mas que possivelmente acabarão nele (MANTOAN, 2006, p. 19).

A mudança na perspectiva de ensino exige que sejam feitas alterações no sistema educacional como um todo e não somente em partes do sistema. Ao analisar as políticas de inclusão escolar em Moçambique, percebemos que há uma responsabilização do papel do professor.

\section{Educação inclusiva no presente}

Neste trabalho, consideramos como período presente dois marcos. O primeiro é o marco da introdução oficial da educação inclusiva, que é caracterizado pelo lançamento do "Projeto Escolas Inclusivas". Esse período vai de 1998 a 2008. O segundo marco temporal é o que vai de 2009 a 2019, que é marcado pelo início do funcionamento dos Centros de Recursos de Educação Inclusiva (2012), pela aprovação da atual Lei do Sistema Nacional de Educação (2018a) e pela aprovação da Estratégia de Educação Inclusiva e Desenvolvimento de Crianças com Deficiência (2018b).

O lançamento do Projeto Escolas Inclusivas é registrado como um marco importante na inclusão de alunos com necessidades educativas especiais em Moçambique. Foi a partir desse projeto que grande parte dos alunos com deficiência passaram a frequentar as escolas de ensino comum. Para atingir os objetivos desse projeto, foi adotado como instrumento de ação o Conjunto de Materiais do Projeto UNESCO intitulado: Formação de Professores, Necessidades Especiais na Sala de Aula, o qual foi implementado em mais de cinquenta países. Esse pacote serviu como uma das portas de entrada das agências multilaterais, que pode ser feita a partir do fluxo de ideias ou por meio de redes políticas que envolvem a circulação internacional de ideias ou ainda pela imposição de algumas "soluções" oferecidas e recomendadas por essas agências, por exemplo Banco Mundial (MAINARDES, 2006). É nesse contexto que as políticas internacionais ganham espaço através da transferência de ideias ou de financiamento para uma determinada ação.

O Projeto Escolas Inclusivas tinha como objetivo prioritário transformar as escolas de ensino comum em "escolas inclusivas". Para o alcance desse objetivo, iniciou-se com a proposição

70 Projeto Escolas Inclusivas tinha como finalidade gerar experiências de atendimento e educação de alunos com necessidades educativas especiais e formar os professores para trabalhar nas escolas consideradas inclusivas. 
da formação de professores, o que foi feito através de seminários de capacitação dos técnicos do Ministério da Educação e dos professores das escolas selecionadas (MANHIÇA, 2000). No Plano Estratégico de Educação 1999-2003, foi adotado o lema "combater a exclusão, renovar a escola" que elege o princípio de inclusão e define que crianças com necessidades educativas especiais serão "integradas" nas escolas de ensino regular e salas de aulas existentes ao invés de segregadas em escolas especiais. Ademais, o Plano reforça que o sucesso da inclusão irá exigir a formação inicial e continuada de professores para que possam responder às necessidades desses alunos (MOÇAMBIQUE, 1999). Há uma continuidade das diretrizes orientadoras da Lei 6/1992 e da Política Nacional de Educação.

Em 2006, foi lançado o segundo Plano Estratégico de Educação e Cultura 2006-2011, com o lema "fazer da escola um pólo de desenvolvimento, consolidando a moçambicanidade" (MOÇAMBIQUE, 2006). Este plano dá diretrizes para a formulação e implementação de atividades na educação inclusiva, reforçando a necessidade da formação de professores para o atendimento dos alunos com necessidades educativas especiais. Foi por conta deste Plano que as políticas de educação inclusiva começaram a ter uma orientação mais definida como o Diploma Ministerial 191/2011, que cria os Centros de Recursos de Educação Inclusiva.

Em 2012, foi implementado um novo Plano Estratégico da Educação 2012-2016, cujo lema foi "construindo competências para um Moçambique em constante desenvolvimento". Este plano foi prorrogado até 2019 e dá continuidade às metas e estratégias anteriores com um destaque especial ao papel dos Centros de Recursos de Educação Inclusiva, que iniciaram suas atividades em 2012.

Chama-se atenção que os Planos Estratégicos de Educação do período em análise referem que o sucesso da inclusão escolar é da responsabilidade do professor. Mas, a escola, sendo um sistema, há a necessidade de investir na preparação de todos os profissionais, no sentido de responder às necessidades dos seus alunos. Essa visão que envolve a atribuição da responsabilidade ou do sucesso da inclusão a um dos elementos do sistema, neste caso, aos professores, pode ser considerada bastante simplificadora e redutora.

Apesar dessa valorização da formação de professores para o sucesso da inclusão, as políticas de massificação do ensino em Moçambique não foram acompanhadas por estratégias de capacitação de professores da rede de ensino comum para garantir o atendimento aos alunos com deficiência e/ou necessidades educativas especiais. Tem-se verificado que os programas de formação de professores não adotam ainda uma componente de educação inclusiva. Uma das propostas vindas do Projeto Escolas Inclusivas foi a introdução da disciplina de educação especial nos programas de formação de professores. Os conteúdos dessa disciplina foram transformados em tópicos na disciplina de Psicopedagogia (CHAMBAL, 2012).

A Lei do Sistema Nacional de Educação refere que:

[...] o objetivo da educação especial é o de proporcionar à criança, jovem e adulto uma formação em todos os subsistemas de educação e a capacitação vocacional que permita a sua integração na sociedade, na vida laboral e na continuação de estudos. O ensino destes alunos realiza-se em escolas regulares e especiais (MOÇAMBIQUE, 2018a, p. 5).

Essa Lei não apresenta o conceito de inclusão, o que pode constituir um desafio na implementação da própria política.

O documento intitulado Estratégia de Educação Inclusiva e Desenvolvimento de Crianças com Deficiência tem como foco a intervenção precoce em caso de diagnóstico da deficiência, envolvimento da família na inclusão da criança em escolas de ensino comum, bem como a formação e a capacitação de professores e outros profissionais envolvidos no atendimento desses alunos. A aprovação desses documentos é um indicativo da articulação do governo em resposta às orientações dos documentos elaborados em nível internacional, dos quais Moçambique é signatário, com 
ênfase naqueles que promovem as políticas de inclusão de alunos com necessidades educativas especiais. Nesse sentido, as escolas de ensino comum passaram a matricular alunos com necessidades educativas especiais e, até 2019, estavam matriculados nessas escolas, (1 a a 12 a classe/série) 76. 843 alunos. Na tabela a seguir, são apresentados os dados dos alunos por tipologia de deficiência, matriculados no período de 2012 a 2019.

Tabela 1: Evolução de matrículas de alunos com necessidades educativas especiais no período 2012 a 2019

\begin{tabular}{|l|c|c|c|c|c|c|c|c|}
\hline & & \multicolumn{6}{|c|}{ ANO } \\
\hline $\begin{array}{l}\text { Tipo de } \\
\text { deficiência }\end{array}$ & 2012 & 2013 & $2014^{8}$ & 2015 & 2016 & 2017 & 2018 & 2019 \\
\hline Visual & 8947 & 4530 & & 13113 & 18261 & 14703 & 12876 & 14479 \\
\hline Auditiva & 14848 & 8963 & & 23030 & 28559 & 25388 & 22959 & 22616 \\
\hline $\begin{array}{l}\text { Deficiência } \\
\text { mental }\end{array}$ & 5889 & 2646 & & & & & & \\
\hline Físico motora & 4042 & 3555 & & 9851 & 13325 & 12667 & 12868 & 12988 \\
\hline $\begin{array}{l}\text { Transtornos de } \\
\text { fala }\end{array}$ & & & 13242 & 18296 & 18436 & 19345 & 19242 \\
\hline $\begin{array}{l}\text { Mais de uma } \\
\text { deficiência }\end{array}$ & 33726 & 19694 & & 64129 & 84820 & 78614 & 74921 & 76843 \\
\hline Total & Ton & & 4893 & 6379 & 7420 & 6873 & 7518 \\
\hline
\end{tabular}

Fonte: Ministério da Educação e Desenvolvimento Humano - Moçambique (2019).

Em relação à frequência dos alunos com necessidades educativas especiais nas escolas de ensino comum, percebemos que houve um aumento significativo de matrículas. Esse aumento é mais visível em 2016, em que estiveram matriculados 84.820 alunos, e os anos seguintes são marcados por uma oscilação.

Ao analisar o período de 2019, percebemos que estavam matriculados no sistema 8.195.958 alunos e, desses, apenas 76.843 eram alunos com necessidades educativas especiais. Apesar de existirem as escolas especiais, que atendem cerca de trezentos alunos com deficiência, e os Centros de Recursos de Educação Inclusiva, que, em 2019, atendiam a um total de 326 alunos com deficiência, percebemos que esse grupo de educandos ainda enfrenta dificuldades de acesso ao ensino.

Assim, apesar de os números de matrículas indicarem um aumento, muitas crianças, adolescentes e jovens com deficiência não chegam a se escolarizar, alguns são matriculados tardiamente e outros são mantidos em casa como forma de protegê-los da discriminação. À medida que o nível de escolaridade aumenta, o número de alunos com necessidades educativas especiais tende a reduzir, o que pode ser justificado pela evasão escolar e pela falta de professores para atender a esses alunos, assim como a falta de vagas para dar continuidade aos estudos, pois a estrutura organizacional do ensino apresenta uma base ampla e o topo afunilado.

Ao analisar por tipologia de deficiência, percebemos que a categoria da deficiência auditiva tem mais alunos, seguida pelos transtornos de fala e a deficiência visual. A partir dos números de matrículas no ensino comum, podemos perceber que houve uma massificação da educação de alunos com necessidades educativas especiais, sendo este um aspecto promissor na ampliação das

\footnotetext{
8 Ausência de dados estatísticos de alunos com necessidades educativas especiais matriculados nas escolas de ensino comum. 
políticas de educação inclusiva. Apesar desse aumento, ainda se verifica casos de alunos que deixam de frequentar a escola por diversos motivos. Uma pesquisa realizada pelo Movimento Educação Para Todos - MEPT - (MOÇAMBIQUE, 2017) apontou que os alunos com necessidades educativas especiais estão mais sujeitos a abandonar a escola por sofrerem discriminação, condições inadequadas de aprendizagem e ausência de professores para atender as particularidades desses alunos. A ausência de professores qualificados é mais visível nos alunos com deficiência auditiva, pois as escolas ainda não possuem intérpretes de língua de sinais de Moçambique nem professores com domínio da língua de sinais. A partir dessas constatações, percebemos que ainda há necessidade de discutir e melhorar as condições de escolarização que são oferecidas a esses alunos, contemplando as dimensões como a sua permanência, o seu aproveitamento escolar e os seus serviços de apoio.

Para Glat et al. (2007), a educação inclusiva é um fenômeno que vai além da matrícula de alunos com necessidades educativas especiais nas escolas de ensino comum, pois "[...] só é significativa se proporcionar o ingresso e a permanência do aluno na escola com aproveitamento acadêmico, e isso só ocorrerá a partir da atenção às suas peculiaridades de aprendizagem desenvolvidas" (GLAT; PLESTSCH; FONTES, 2007, p. 344-345). Uma escola inclusiva exige a colaboração de todos no processo e, principalmente, a necessidade de melhorar as condições de acesso e de ter profissionais preparados para atender a este grupo de alunos.

$\mathrm{O}$ atual momento da educação de alunos com necessidades educativas especiais em Moçambique é caracterizado pela busca e pela ampliação de atendimento desses educandos e pela disseminação de ações que mantenham os alunos na escola, o que pode ser visualizado pela introdução de disciplinas como Sistema Braille, Língua de Sinais de Moçambique e Necessidades Educativas Especiais nos currículos de Formação de Professores e Educadores de Adultos e também pela introdução do curso de Licenciatura em Língua de Sinais de Moçambique pela Faculdade de Educação da Universidade Eduardo Mondlane.

Considerando o contexto atual em que os debates sobre escolarização de alunos com necessidades educativas especiais tendem a expandir, percebemos que há necessidade de refletir sobre a articulação das políticas educacionais inclusivas e pensar em alternativas que possibilitem a expansão ou a melhoria das condições em que decorre o processo de ensino e aprendizagem desses alunos.

Ao longo deste trabalho, percebemos que as políticas educacionais no país estão focadas na ampliação de acesso dos alunos com necessidades educativas especiais como resposta à escolaridade obrigatória proclamada na Declaração de Dakar, da qual Moçambique é signatário. Em contrapartida, não se verifica investimento nos serviços de apoio (intérpretes, professores de apoio) e especializados para esse grupo de alunos, como orienta a Declaração de Salamanca. Nesse sentido, volta-se a destacar a importância de se olhar para a inclusão escolar como um processo e, como tal, inserido em um sistema, constituído de diferentes elementos. Não podemos restringir a responsabilidade sobre o sucesso do processo de inclusão escolar apenas a um dos elementos do sistema, mas, sim, precisamos investir na qualificação de todos os aspectos que se articulam a este.

\section{Perspectivas da educação inclusiva em Moçambique}

Ao tornar as escolas inclusivas, o Estado dá início à criação de condições de acesso de pessoas com necessidades educativas especiais à educação. Uma das respostas para o atendimento dos alunos com deficiência foi a abertura dos Centros de Recursos e Educação Inclusiva (CREI), que atendem a alunos com e sem necessidades educativas especiais. O Diploma Ministerial 191/2011 que cria esses centros atribui-lhes como competências o ensino, a formação, o diagnóstico, a orientação para as crianças e os jovens com necessidades educativas especiais, capacitação de professores em estratégias de ensino, produção de material didático e aconselhamento (MOÇAMBIQUE, 2011). 
A localização estratégica desses centros, um em cada região do país, poderia dar-lhes uma posição privilegiada para o desenvolvimento da educação inclusiva se as suas atividades fossem abrangentes a todas as províncias, mas ainda enfrentam dificuldades na expansão de suas atividades, por falta de profissionais para atender alunos com necessidades educativas especiais, no sentido de dar assistência e apoio aos professores que atendem nessas escolas.

A dupla função desses centros - o ensino e a capacitação de professores - constitui uma riqueza para o aperfeiçoamento da educação inclusiva no país, pois podem servir como polos de desenvolvimento em matérias de educação inclusiva. Apesar desses avanços, ainda se constitui como um desafio a revitalização desses centros, no sentido de dinamizar as atividades desenvolvidas nessas instituições.

Para Nhapuala e Almeida (2016), o crescimento exponencial de alunos com NEE nas escolas de ensino comum em Moçambique vem colocar desafios enormes às escolas e aos professores, no sentido de responderem às necessidades decorrentes da inclusão, sobretudo em um contexto em que a formação de professores tem-se mostrado em descompasso com as necessidades cotidianas com as quais estes se deparam nas salas de aulas.

Ao proceder a leitura dos documentos normativos, percebemos que estes referem que o sucesso da inclusão é da responsabilidade dos professores. Em contrapartida, ao considerar o período de análise das políticas educacionais de inclusão escolar, percebemos que vários modelos de formação de professores foram adotados no país, mas nenhum desses modelos prioriza a educação especial nos seus planos de estudos. Uma pesquisa realizada por Chambal (2012) apontou que há uma defasagem entre o estabelecido nos documentos de políticas educacionais e o que efetivamente ocorre no contexto da prática, em relação à formação de professores. Essa pesquisa apontou que nas instituições de formação de professores pouco se aborda sobre necessidades educativas especiais e, mesmo quando é tratada, continua sendo apresentada de maneira generalista, de forma que não proporciona aos professores competências básicas para atender a esse grupo de alunos.

Apesar de a formação de professores ser defendida nos documentos analisados como necessária para o sucesso da inclusão, verificamos que houve pouco investimento no sentido de maximizar e potencializar esses profissionais em estratégias inclusivas. Recentemente, em 2019, os programas de formação de professores foram ajustados e passaram a integrar disciplinas como Necessidades Educativas Especiais, Sistema Braille e Língua de Sinais de Moçambique. Ao abordar a formação de professores, salientamos que há necessidade de garantir que na formação inicial e continuada sejam abordados conteúdos articulados com ações práticas que permitam ao professor orientar as aulas e que tais práticas tornem o processo de ensino e aprendizagem mais significativo para os alunos com necessidades educativas especiais.

A trajetória da educação inclusiva em Moçambique tem indicado alterações que direcionam para uma sintonia com as diretrizes internacionais. No entanto, há claros indícios de que continuam existindo dificuldades como a formação efetiva dos professores em disciplinas de educação inclusiva, a falta de profissionais de apoio nas escolas, assim como, nos Centros de Recursos de Educação Inclusiva. Esses Centros constituem uma promessa na dinâmica da inclusão, mas há necessidade de serem revitalizados de modo a responder satisfatoriamente às atribuições deste espaço de ensino, aprendizagem e capacitação dos professores.

Ao longo deste trabalho, podemos perceber que as políticas educacionais no país tendem a ser direcionadas para a inclusão escolar, mas ainda há necessidade de investir na formação de professores. Há necessidade de repensar a valorização dos profissionais, pois, ao assumir a perspectiva inclusiva, precisa-se criar condições de acessibilidade dos alunos com necessidades educativas especiais e de repensar a criação de equipe de profissionais, de modo a prover o necessário para esses alunos e professores. Além disso, há necessidade de repensar a qualificação da compreensão da inclusão escolar como um processo que depende de vários envolvidos. 
Em síntese, esta pesquisa tentou mostrar os desafios e as possibilidades da inclusão escolar em Moçambique. Consideramos como desafio a ampliação dos debates sobre políticas de inclusão, no sentido de permitir o acesso, a permanência e a aprendizagem desses alunos. Passados mais de vinte anos após as escolas adotarem a perspectiva inclusiva, compreendemos que foram feitos movimentos no sentido de responder a essa orientação, mas ainda há necessidade de pensar na constituição de dinâmicas que envolvam a presença de profissionais de apoio, de intérpretes e de outros profissionais nas escolas de ensino comum.

\section{Referências}

BAPTISTA, Cláudio Roberto. "Batesonianas": uma aventura entre a epistemologia e a educação. In: BAPTISTA, Cláudio Roberto; CAIADO, Kátia Regina Moreno; JESUS, Denise Meyrelles de. Educação Especial: diálogo e pluralidade. Porto Alegre: Mediação, 2008.

BRASIL. Política nacional de educação especial na perspectiva da educação inclusiva. Revista Inclusão, Brasília, DF, v. 4, n. 1, p. 7-17, jan./jun. 2008.

CHAMBAL, Luís Alfredo. A formação inicial de professores para a inclusão escolar de alunos com deficiência em Moçambique. 2012. Tese (Doutorado) - Programa de Educação. História Política e Sociedade, Pontifícia Universidade Católica de São Paulo, São Paulo, 2012.

FARENZENA, Nalú. Responsabilidade pública para com as políticas públicas de educação: algumas reflexões. Políticas Educativas, Porto Alegre, v. 5, n. 1, p. 96-112, 2011.

GIL, António Carlos. Métodos e técnicas de pesquisa social. 6. ed. São Paulo: Atlas, 2008.

GLAT, Rosana; PLETSCH, Márcia Denise; FONTES, Rejane de Souza. Educação inclusiva \& educação especial: propostas que se complementam no contexto da escola aberta à diversidade. Revista do Centro de Educação, v. 32, n. 2, 2007, p. 343-355. Universidade Federal de Santa Maria. Santa Maria, RS, Brasil. Disponível em: http://www.redalyc. org/articulo.oa?id=117117241006. Acesso em: 10 nov. 2020.

MAINARDES, Jefferson. Abordagem do ciclo de políticas: uma contribuição para a análise de políticas educacionais. Educação e Sociedade. Campinas, v. 27, n. 94, p. 47-69, jan./abr. 2006.

MANHIÇA, Carlos. Projeto Escolas Inclusivas. Relatório preliminar da fase piloto. Um contributo para o combate à exclusão escolar e a melhoria da qualidade de ensino através da valorização profissional do professor na formação contínua. Ministério da Educação. Maputo, 2000.

MANTOAN, Maria Teresa Égler. Igualdade e diferenças na escola como andar no fio da navalha. Educação, Porto Alegre: PUC/RS, v. 29, v. 58, n. 1, p. 55-64, 2006.

MATURANA, Humberto; VARELA, Francisco. A Árvore do Conhecimento. As bases biológicas da compreensão humana, 9. ed. São Paulo: Palas Athena, 2001.

MAZULA, Brazão. Educação, cultura e ideologia em Moçambique: 1975-1985. Lisboa: Edições Afrontamento, 1995.

MOÇAMBIQUE. Lei no 4/83 do Sistema Nacional de Educação. Maputo. 1983.

MOÇAMBIQUE. Lei no 6/92 do Sistema Nacional de Educação. Maputo. Imprensa Nacional, 1992.

MOÇAMBIQUE. Política Nacional de Educação e estratégias de implementação. Maputo. Ministério da Educação, 1995.

MOÇAMBIQUE. Ministério da Educação. Programa de atendimento psicopedagógico à criança com necessidades educativas especiais. MINED - Departamento de ensino primário/educação especial. Maputo, 1996.

MOÇAMBIQUE. Plano Estratégico de Educação 1999-2003: Combater a Exclusão, Renovar a Escola. Maputo, 1999.

MOÇAMBIQUE. Plano Estratégico de Educação e Cultura 2006-2010/11. Fazer da escola um polo de desenvolvimento consolidando a Moçambicanidade. Maputo, 2006.

MOÇAMBIQUE. Diploma ministerial no 191/2011. Criação dos centros de recurso e educação inclusiva. Maputo: MINED, 2011. 
MOÇAMBIQUE. Instituto Nacional de Estatística. Censo Geral da população. Maputo, 2017.

MOÇAMBIQUE. MEPT. Estudo Sobre a Situação das Infraestruturas Escolares e seu Impacto no Acesso para as Crianças com Deficiência no Ensino Primário na Província de Maputo, 2017.

MOÇAMBIQUE. Lei no 18/2018 do Sistema Nacional de Educação. Boletim da Republica I Serie, n. 254. Maputo: Imprensa Nacional E.P, 2018

MOÇAMBIQUE. Lei nº1/2018 da Revisão Pontual da Constituição da República. Maputo. Imprensa Nacional E.P, 2018a

MOÇAMBIQUE. Ministério da educação e desenvolvimento humano. Estratégia de Educação Inclusiva e Desenvolvimento da Criança. Maputo, 2018b.

MULLER, Pierre; SUREL, Iyes. Análise das políticas públicas. Pelotas: Educat, 2002.

NHAPUALA, Gildo. A. Formação psicológica inicial de professores: atenção à educação inclusiva em Moçambique. 2014. 199 f. Tese (Doutorado em Psicologia da Educação) - Universidade do Minho, Local, 2014.

NHAPUALA, Gildo; ALMEIDA, Leandro. Formação de Professores e Inclusão em Moçambique. Universidade do Minho, Journal of Research in Special Educational Needs, v. 16, p. 520-523, 2016. Disponível em: https://onlinelibrary. wiley.com/doi/epdf/10.1111/1471- 3802.12314. Acesso em: 15 abr. 2020.

SIMBINE, Alexandra Justino. Concepções da deficiência: embates entre as versões ocidentais e contemporâneas em Moçambique. 2016. Dissertação (Mestrado em Psicologia) - Universidade Federal Fluminense, Instituto de Ciências Humanas e Filosofia, Departamento de Psicologia, 2016.

UNESCO. Declaração Mundial sobre Educação para Todos: Satisfação das Necessidades Básicas de Aprendizagem. Jomtien, 1990.

UNESCO. Conferência Mundial sobre Necessidades Educativas Especiais: Acesso e Qualidade. Salamanca, 1994.

UNESCO. Educação para todos: o compromisso de Dakar. Dakar: UNESCO, 2000.

VASCONCELLOS, Maria José Esteves. Pensamento Sistêmico: o novo paradigma da ciência. Campinas: Papirus, 2016.

Data de submissão: 14/05/2021

Data de aceite: 02/07/2021 